\title{
Epidemiology of patients with bad cervix attending gynaecology OPD of a tertiary care centre in Western Uttar Pradesh, India
}

\author{
Kriti Bhatnagar $^{1 *}$, Kalpana Baghel ${ }^{2}$
}

\begin{abstract}
${ }^{1}$ Associate Professor, ${ }^{2}$ Assiatant Professor, Department of Obstetrics and Gynecology, Muzaffarnagar Medical College, Muzaffarnagar, Uttar Pradesh, India
\end{abstract}

Received: 06 January 2017

Accepted: 28 January 2017

\author{
*Correspondence: \\ Dr. Kriti Bhatnagar, \\ E-mail: drkriti.bhatnagar@gmail.com
}

Copyright: () the author(s), publisher and licensee Medip Academy. This is an open-access article distributed under the terms of the Creative Commons Attribution Non-Commercial License, which permits unrestricted non-commercial use, distribution, and reproduction in any medium, provided the original work is properly cited.

\begin{abstract}
Background: Cervical cancer is one of the biggest health problems of women around the world. An estimated 4,70,000 new cases are diagnosed worldwide annually with about $80 \%$ of these being in developing countries with India contributing to about a quarter of it. Pap smear and colposcopy are two non-invasive methods for screening of cervical cancer with varying sensitivity and specificity. This study uses these along with histopathology to find out premalignant lesions in women of rural western Uttar Pradesh, India and to find their correlation with various sociodemographic features.

Methods: This prospective clinical study was carried out in department of Obstetrics and Gynaecology in Muzaffarnagar Medical College from $1^{\text {st }}$ January 2012 to $31^{\text {st }}$ December 2014. Those patients who fulfilled the inclusion criteria had their Pap smear done at first visit followed by colposcopy when cytology report was available. Colposcopically indicated biopsy was done only in those patients who had suspicious areas on colposcopy.

Results: Out of total 500 women included in the study majority although having a bad cervix were having a normal pap smear (45\%). LSIL and HSIL were present in $17.4 \%$ and $9.8 \%$ respectively. Squamous metaplasia was the most common abnormal finding seen in $12.2 \%$ of cases followed by acetowhite areas (7.6\%). Only 137 patients who had abnormal colposcopic findings were subjected to biopsy.

Conclusions: In present study it was found that increasing age, early age at coitarche and high parity are risk factors for high grade lesions. Colposcopy served as a tool to decrease the need for invasive procedure i.e biopsy.
\end{abstract}

Keywords: Colposcopy, HSIL, LSIL

\section{INTRODUCTION}

Cervical cancer is one of the biggest health problems of women around the world. Cervical cancer is the most common malignancy affecting Indian women. An estimated 4,70,000 new cases are diagnosed worldwide annually with about $80 \%$ of these being in developing countries with India contributing to about a quarter of the global burden of cervical cancer. ${ }^{1}$ According to ICMR cancer cervix is the third most common cancer in India. ${ }^{2}$ The annual number of new cases in India was 122844 in 2012. ${ }^{3}$ In Uttar Pradesh alone 18692 new cases were reported in $2012 .{ }^{3}$ All over India ICMR estimated 1 lakh new cases in 2016 and about 1.04 lakh during $2020 .^{2}$
India represents $26.4 \%$ of all women dying of cervical cancer globally. ${ }^{1}$ One woman dies every 8 minute in India due to cervical cancer. ${ }^{4}$ Despite of the fact that more than $80 \%$ of cervical cancer cases are in developing countries, only $5 \%$ of women have ever been screened for cervical abnormalities. ${ }^{5}$

In routine practice a simple per speculum examination may many a time just dismiss a precancerous lesion as erosion. Here comes the role of cytology and colposcopically. The PAP smear is a simple, safe, noninvasive and effective method for screening of cancer cervix. ${ }^{6}$ and its use has shown to be effective in reducing the prevalence of cervical cancer (by 79\%) and associated 
mortality (by 70\%).,8 However the sensitivity of pap smear in detecting high grade lesions is low i.e $55.4 \%$ and $96.8 \%$ for CIN II and CIN III respectively thus increasing the chances of false negative cases. ${ }^{9}$

The New Bethedsa System 2001 is the most commonly used and most widely accepted classification to report cervical smear samples and the same was used in this study to interpret pap smear. Premalignant lesions are characterized by abnormal cellular or epithelial architecture in the areas surrounding the squamocolumnar junction. In this, squamous cell abnormality is divided into three categories- atypical squamous cells (ASC), low grade squamous intraepithelial lesions (LSIL), high grade squamous intraepithelial lesions (HSIL). ${ }^{10}$

It was in 1925 that Hinsellman first hypothesized visualization of cervical epithelium under magnification. ${ }^{11}$ Nowadays colposcopy is an integral part of the management of women presenting with abnormal cervical cytology and those with lesions in the lower genital tract indicative of intraepithelial neoplasia. it is a simple, non-invasive procedure which helps in determining the location, size and extent of abnormal cervical lesions and serves for detecting the site for biopsies. ${ }^{12}$

Colposcopy is complementary to cytology. ${ }^{12}$ As the histopathology remains the gold standard so the final diagnosis must be made on histopathological examination. ${ }^{12}$ The importance of all these screening methods is increased by the fact that cervical cancer is having a long pre-invasive phase in which it can be detected and treated effectively. ${ }^{13}$

The past decade has witnessed several changes in the realm of cervical cancer screening, prevention, and management. These include the increased use of liquid-based preparations; the addition of co-testing (Pap and hrHPV testing) and, more recently, primary hrHPV testing as additional screening options; further insights into HPV biology; changes in histopathology terminology; approval and implementation of prophylactic HPV vaccines, and updated guidelines for cervical cancer screening and clinical management. ${ }^{14}$

\section{METHODS}

This prospective clinical study was carried out in department of Obstetrics and Gynaecology in Muzaffarnagar Medical College from $1^{\text {st }}$ January 2012 to $31^{\text {st }}$ December 2014, after taking approval from the institutional ethical committee.

The study selected 500 women randomly among the patients attending the gynaecology OPD who met the inclusion criteria. After taking detailed history about age, parity, socio economic status, education, history of tobacco intake, age at marriage, general examination, systemic examination and local examination, patients were selected.

\section{Inclusion criteria}

- $\quad$ Sexually active female of age 20-65 years.

- Married.

- Features of Suspicious cervix on visual inspectionerosion, chronic cervicitis, healed lacerations, hypertrophic cervix, bleeds on touch, suspicious lesion on the cervix.

- Presenting with abnormal vaginal discharge, irregular menstrual bleeding, post-menopausal bleeding, post coital bleeding.

- Patients undergone supracervical hysterectomy.

\section{Exclusion criteria}

- Pregnancy.

- Features of frank invasive carcinoma on visual inspection.

- Women who have used vaginal medications or contraception in the last 48 hours of examination.

- Acute infection.

- Women with bleeding per vaginum at the time of examination.

- Women who has undergone total hysterectomy.

Written informed consent was taken and procedure was explained to all the patients included in the study. At the first visit Pap smear was done using Liquid based cytology. Colposcopy was done after the cytology report was available. Colposcopically indicated biopsy was done only in those patients who had suspicious areas on colposcopy.

\section{RESULTS}

The study was conducted over 500 patients who fulfilled the inclusion criteria. As seen in Table 1 out of the 500 patients included in the study maximum were in the age group of 31-40 years i.e. $250(50 \%)$ patients followed by $41-50$ years age group having $156(31.2 \%)$ patients.

Table 1: Age distribution of patients.

\begin{tabular}{|ll|}
\hline Age (years) & No. of patients (\%) \\
\hline $20-30$ & $67(13.4)$ \\
\hline $31-40$ & $250(50)$ \\
\hline $41-50$ & $156(31.2)$ \\
\hline $51-60$ & $22(4.4)$ \\
\hline$>60$ & $5(1)$ \\
\hline
\end{tabular}

\section{Level of literacy}

Out of the total 500 patients included in the study $64.6 \%$ were literate and $35.4 \%$ were illiterate. Maximum patients had primary level education $\left(1^{\text {st }}-5^{\text {th }}\right.$ standard $)$ i.e. 
$48 \%(n=240)$. Thus, this low level of education can be correlated to poor awareness.

As seen in Table 2 maximum women were having a parity of $3-4$ i.e. $51.2 \%$ and $22 \%$ had a parity of 5 or more.

Table 2: Parity of patients.

\begin{tabular}{|ll|}
\hline Parity & No. of patients ( \%) \\
\hline Nullipara & $2(0.4)$ \\
\hline $1-2$ & $132(26.4)$ \\
\hline $3-4$ & $256(51.2)$ \\
\hline$\geq 5$ & $110(22)$ \\
\hline
\end{tabular}

This Table 3 shows the distribution of the subjects according to their socioeconomic status. As can be seen $75.8 \%$ of patients belong to the lower socioeconomic status group. That correlates well with the fact that the incidence of PID and pre-invasive lesions of the cervix is more in poor socioeconomic group. No patient in our study belonged to the upper class.

Table 3: Socioeconomic status of patients.

\begin{tabular}{|ll|}
\hline Class & No. of patients $(\%)$ \\
\hline I & $0(0)$ \\
\hline II & $2(0.4)$ \\
\hline III & $33(6.6)$ \\
\hline IV & $96(19.2)$ \\
\hline V & $379(75.8)$ \\
\hline
\end{tabular}

As seen in the above Table 4 out of the total 500 patients included in the study tobacco use (smoking and tobacco chewing) was found in $67.2 \%(n=336)$ patients while $32.8 \%(n=164)$ did not use any form of tobacco.

Table 4: Pattern of tobacco use among patients.

\begin{tabular}{|llc|}
\hline Tobacco use & Percentage & Number of patents \\
\hline Yes & 67.2 & 336 \\
\hline No & 32.8 & 164 \\
\hline
\end{tabular}

As seen in Table 5 maximum number of patients had first coitus at age of 16-20 years. 88.6\% (443/500) women were married off before 20 years of age.

Table 5: Age of patients at first intercourse.

\begin{tabular}{|ll|}
\hline Age at first intercourse (years) & Number $(\%)$ \\
\hline $11-15$ & $99(19.8)$ \\
\hline $16-20$ & $344(68.8)$ \\
\hline$>20$ & $57(11.4)$ \\
\hline
\end{tabular}

As seen in Table 6, $58 \%$ of the females included in the study did not use any contraceptive method. Barrier was the most common method used by $30.2 \% \quad(n=151)$ followed by IUCD i.e $6.6 \%(n=33)$. The least common method used was OCPs used by only $5.2 \%(n=26)$.

Table 6: Pattern of contraceptive use among patients.

\begin{tabular}{|ll|}
\hline Method of contraception used & Number (\%) \\
\hline Not using any method & $290(58)$ \\
\hline OCP & $26(5.2)$ \\
\hline IUCD & $33(6.6)$ \\
\hline Barrier method & $151(30.2)$ \\
\hline
\end{tabular}

As seen in Table 7 white discharge per vaginum $(66.4 \%)$, Lower abdominal pain $(59.2 \%)$ and backache $(58.5 \%)$ were among the most commonly present symptom in the patients having unhealthy cervix. Post coital bleeding was seen in only $2.4 \%$ of the cases however $7 \%$ of women presenting with post-menopausal bleeding were found to have an unhealthy cervix.

Table 7: Distribution of patients according to presenting complaint.

\begin{tabular}{|ll|}
\hline White discharge per vaginum & $332(66.4)$ \\
\hline Lower abdominal pain & $296(59.2)$ \\
\hline Backache & $294(58.8)$ \\
\hline AUB & $45(9)$ \\
\hline Postcoital bleeding & $12(2.4)$ \\
\hline Postmenopausal bleeding & $7(1.4)$ \\
\hline
\end{tabular}

As seen in Table 8 majority of the women although having a bad cervix were having a normal pap smear i.e $45 \%$. LSIL and HSIL were present in $17.4 \%$ and $9.8 \%$ respectively. Only 1 patient out of 500 had $\mathrm{ASCH}$ and ASCUS was seen in $38(7.6 \%)$ patients.

Table 8: Cytology findings of patients.

\begin{tabular}{|ll|}
\hline Pap smear report & \multicolumn{1}{c|}{ No. of patients $(\%)$} \\
\hline NILM & $225(45)$ \\
\hline ASCUS & $38(7.6)$ \\
\hline ASCH & $1(0.2)$ \\
\hline LSIL & $87(17.4)$ \\
\hline HSIL & $49(9.8)$ \\
\hline
\end{tabular}

Table 9: Colposcopy findings of patients.

\begin{tabular}{|lll|}
\hline Colposcopy findings & $\begin{array}{l}\text { No. of } \\
\text { patients }(\%)\end{array}$ \\
\hline & Normal & $363(72.6)$ \\
\hline & Squamous metaplasia & $61(12.2)$ \\
\cline { 2 - 3 } & Acetowhite areas & $38(7.6)$ \\
\cline { 2 - 3 } Satisfactory & $\begin{array}{l}\text { Coarse } \\
\text { punctuations/mosaic }\end{array}$ & $19(3.8)$ \\
\cline { 2 - 3 } & Abnormal vessels & $5(1)$ \\
\hline Unsatisfactory & $14(2.8)$ \\
\hline
\end{tabular}

Out of all the 500 patients subjected to colposcopy most had satisfactory colposcopy (486 i.e. $97.2 \%$ ) only $2.8 \%$ 
were having unsatisfactory colposcopy. In those with satisfactory colposcopy majority of patients $(72.6 \%) \mathrm{did}$ not have any abnormal finding on colposcopy. Squamous metaplasia was the most common abnormal finding seen in $12.2 \%$ of cases followed by acetowhite areas (7.6\%), coarse punctuations/mosaic (3.8\%), abnormal vessels (1\%) respectively (Table 9 ).

Table 10: Histopathology findings of the patients.

\begin{tabular}{|ll|}
\hline Histopathology finding & No. of patients (\%) \\
\hline Normal & 1 \\
\hline Chronic cervicitis & 39 \\
\hline Squamous metaplasia & 7 \\
\hline CIN I & 60 \\
\hline CIN II & 26 \\
\hline CIN III & 4 \\
\hline Invasive Carcinoma & 0 \\
\hline
\end{tabular}

Out of the total 500 patients included in the study and subjected to colposcopy 137 patients with abnormal and unsatisfactory colposcopic findings were subjected to histopathological examination.

\section{DISCUSSION}

Out of the 500 patients included in the study maximum were in the age group of 31-40 years i.e. $250(50 \%)$ patients followed by 41-50 year age group having 156 $(31.2 \%)$ patients. This was similar to the results seen in another study done in same region in which maximum patients were in 30-39 years of age group. ${ }^{15}$

Maximum patients had primary level education $\left(1^{\text {st }}-5^{\text {th }}\right.$ standard $)$ i.e. $48 \% \quad(n=240)$. Thus, this low level of education can be correlated to poor awareness regarding hygiene, symptoms of PID and will to seek early treatment for any type of PID.

In present study $75 \%$ of patients belong to the lower socioeconomic status group. That correlates well with the fact that the incidence of PID and pre-invasive lesions of the cervix is more in poor socioeconomic group. No patient in our study belonged to the upper class.

In the present study majority of women i.e. $67.2 \%$ $(n=336)$ were having tobacco use (smoking, passive smoking and tobacco chewing). This correlates well with the fact that any form of tobacco use is associated with an increased risk of developing cervical dysplasia. ${ }^{16}$

In present study maximum number of patients had first coitus at age of 16-20 years. 88.6\% (443/500) women were married off before 20 years of age.

In the present study only $42 \%$ of patients were using some form of contraception and in those who were using, barrier which is a method with a high failure rate was used by the majority. Lesser use of contraception results in high parity which is a well-known risk factor for all the premalignant lesions of the cervix.

In present study most of the patients had more than one complaint and white discharge per vaginum being the commonest one i.e. $66.4 \%$. Many other studies have also shown similar results. ${ }^{12,17,18}$ and the association of white discharge vaginally with premalignant of cervix has been well established. ${ }^{18}$

In present study maximum number of patients had first coitus at age of 16-20 years and 88.6\% (443/500) women were married off before 20 years of age. Early age at coitarche has been found to be associated with persistence of infection and occurrence of premalignant lesions.

In present study 225 patients had normal pap smear while $275(45 \%)$ had abnormal pap smear. The most common abnormality seen was LSIL seen in $17.4 \%$ followed by HSIL seen in $9.8 \%$ of cases. So, maximum number of patients although symptomatic had normal pap smear. In a similar study including 450 patients with bad cervix Barut et al found NILM, LSIL, HSIL in $87.5 \%, 3.8 \%$, $1.6 \%$ respectively. ${ }^{19}$ However NILM, LSIL, HSIL was found in $96.8 \%, 1.36 \%, 0.9 \%$ and $64 \%, 17 \%, 12 \%$ of cases respectively in studies done by Gupta et al and Joshi et al respectively. ${ }^{11,15}$ The high percentage of LSIL and HSIL seen in our study may be due to the fact that the patients included in our study were all symptomatic and having a grossly bad cervix on per speculum examination so the probability of finding an abnormal smear in these patients is naturally high.

Colposcopy was done in all patients including those with inflammatory pap smear to rule out false positive cases in cytology (when compared with colposcopy). No abnormal colposcopic finding was present in 363 patients. This group included some patients $(n=138)$ who had abnormal cytology so after colposcopy they were saved from any further invasive procedure of biopsy cervix and were kept on regular follow up. Colposcopy was unsatisfactory in 14 patients. Most common abnormality seen on colposcopy was squamous metaplasia (seen in $12.2 \%$ i.e. $n=61$ patients) followed by persistent acetowhite areas seen in $76 \%$ i.e. $n=38$ patients.

On Biopsy CINI was the most common abnormality seen in 60 out of 137 patients $(43.79 \%)$ followed by Chronic cervicitis (39 out of 137 i.e. 28.46\%). Benign lesions on HPE were found in $72.25 \%$ of patients (that means these patients did not require definitive surgical treatment for malignancy).

Most of these patients just required cryocautery with antibiotic and were in regular follow up. Out of the $27.25 \%$ patients having high grade lesions on HPE the most common pre-invasive lesion seen was CIN II i.e. $18.97 \%$ patients. Seven patients $(5 \%)$ had squamous 
metaplasia confirmed on HPE (on colposcopy 61 patients had squamous metaplasia). None of the patients was found to have invasive carcinoma on HPE.

Table 11: Correlation of LSIL/HSIL with age.

\begin{tabular}{|llll|}
\hline Age (years) & No. of patients & LSIL & HSIL \\
\hline $20-30$ & 67 & 14 & 1 \\
\hline $31-40$ & 250 & 20 & 16 \\
\hline $41-50$ & 156 & 25 & 12 \\
\hline $51-60$ & 22 & 4 & 18 \\
\hline$>60$ & 5 & 1 & 2 \\
\hline Total & 500 & 87 & 49 \\
\hline
\end{tabular}

As can be seen in Table 11 maximum incidence of LSIL was seen in 20-30 years of age group. Maximum number of patients with HSIL were of 51-60 years of age. It was seen that the incidence of HSIL increases with age. This is consistent with the fact that age is a risk factor for HSIL.

Table 12: Correlation of LSIL/HSIL with parity.

\begin{tabular}{|llll|}
\hline Parity & No. of patients & LSIL & HSIL \\
\hline Nulliparous & 2 & 0 & 0 \\
\hline $1-2$ & 132 & 14 & 5 \\
\hline $3-4$ & 256 & 34 & 25 \\
\hline$\geq 5$ & 110 & 39 & 19 \\
\hline Total & 500 & 87 & 49 \\
\hline
\end{tabular}

As can be seen in Table 12 maximum incidence of LSIL/HSIL has been seen in patients with maximum parity. As the parity advances the incidence of LSIL/HSIL increases. No HSIL/LSIL was seen in nulliparous patients. So, patients with high parity should always be included in the screening irrespective of their symptoms.

As seen in Table 13 maximum HSIL was seen in patients who had first coitus before 15 years of age. The more prolonged was the sexual history more were the chances of developing HSIL.

Table 13: Correlation of LSIL/HSIL with age at first coitus.

\begin{tabular}{|llll|}
\hline $\begin{array}{l}\text { Age at first coitus } \\
\text { (years) }\end{array}$ & $\begin{array}{l}\text { No. of } \\
\text { patients }\end{array}$ & LSIL & $\begin{array}{l}\text { HSI } \\
\text { L }\end{array}$ \\
\hline $11-15$ & 99 & 23 & 20 \\
\hline $16-20$ & 344 & 37 & 19 \\
\hline$>20$ & 57 & 27 & 10 \\
\hline Total & 500 & 87 & 49 \\
\hline
\end{tabular}

As seen in Table 14 maximum number of patients who had HSIL/LSIL presented with AUB (intermenstrual/post coital/post-menopausal bleeding). Maximum incidence of HSIL was seen in patients who presented with postmenopausal bleeding however maximum number of patients with LSIL $(n=87)$ presented with white discharge per vaginum $(n=40)$.

Table 14: Correlation of LSIL/HSIL with presenting complaint.

\begin{tabular}{|llll|}
\hline Presenting complaint & $\begin{array}{l}\text { No. of } \\
\text { patients }\end{array}$ & LSIL & HSIL \\
\hline White discharge & 332 & 40 & 12 \\
\hline Lower abdominal pain & 296 & 14 & 8 \\
\hline Backache & 294 & 12 & 5 \\
\hline Intermenstrual bleeding & 45 & 14 & 10 \\
\hline Post coital bleeding & 12 & 4 & 8 \\
\hline Post-menopausal bleeding & 7 & 1 & 6 \\
\hline Total & 500 & 87 & 49 \\
\hline
\end{tabular}

\section{CONCLUSION}

Ensuring high levels of participation, sufficient health care infrastructure and human resources are important for effective screening for premalignant lesions. Pap smear is a test with very low sensitivity when compared to colposcopy especially for HSIL. Colposcopy has a higher sensitivity. Both these modalities are not competitive they are complementary to each other. Colposcopy helps to do site specific biopsy and reduce the total number of patients requiring Biopsy after pap smear screening moreover colposcopy helps to localize the exact site of biopsy thereby reducing the number of incidence of false negative samples. Thereby utilizing the scarce medical resources maximally in resource poor settings.

In present study we found that increasing age, early age at coitarche and high parity are risk factors for high grade lesions. Screening for cervical cancer should be done in all women in reproductive and menopausal age group. No opportunity for screening should be missed if any women in this age group comes to us with any complaint whatsoever. In the present study it was found that out of the total 500 patients included in the study and subjected to colposcopy biopsy was required only in 137 required biopsy. That means colposcopy served as a tool to decrease the need for invasive procedure i.e. biopsy.

Funding: No funding sources

Conflict of interest: None declared

Ethical approval: The study was approved by the Institutional Ethics Committee

\section{REFERENCES}

1. Sankarnarayan R, Nene BM, Dinshaw K, Rajkumar R, Shastri S, Wesley R, et al. Early detection of Cervical Cancer with visual inspection methods: A summary of completed and on- going studies in India. Salud Publica Mex. 2003;45(3):S399-407.

2. Over 17 lakh new cancer cases in India by 2020: ICMR. Available at http://www.mid-day.com/ articles/over-17-lakh-new-cancer-cases-in-india-by-202 0-icmr/17248152. 
3. Bruni L, Barrionuevo-Rosas L, Albero G, Serrano B, Mena M, Gómez D, Muñoz J, Bosch FX, de Sanjosé S. ICO Information Centre on HPV and Cancer (HPV Information Centre). Human Papillomavirus and Related Diseases in India. Summary Report 15 December 2016. [Date Accessed in December 2016].

4. Parkin FJ, Pisani P. GLOBAN 2002: Cancer incidence, mortality and prevalence worldwide version IARC Cancer Base No.5; Lyon: IARC Press: 2005.

5. World Health Organization. Comprehensive Cervical cancer control: a guide to essential practice. Geneva, WHO: 2006.

6. Kohli B, Arya BS. Comparison of Pap smear and colposcopy in detection of premalignant lesions of cervix. J South Asian Fed Menopause Soc. 2014;2(1):58.

7. Peirson L, Fitzpatrick-Lewis D, Ciliska D, Warren R. Screening for cervical cancer: a systematic review and meta-analysis. Syst Rev. 2013;2(35):1-14.

8. Ries L, Melbert D, Krapcho M, Stinchcomb D, Howlader N, Horner M, et al. SEER cancer statistics review, 1975-2005. Bethesda, MD: National Cancer Institute. 2008:1975-2005.

9. Mayrand MH, Duarte-Franco E, Rodrigues I, Walter SD, Hanley J, Ferenczy A, et al. Human papillomavirus DNA versus Papanicolaou screening tests for cervical cancer. New England J Med. 2007;357(16):1579-88

10. Berek JS. Intraepithelial Disease of the Cervix, Vagina and Vulva. In: Berek and Novaks Gynaecology; 15th ed: Lippincott Williams and Wilkins; 2007: 583.

11. Joshi C, Kujur P, Thakur N. Correlation of pap smear and colposcopy in relation to histopathological findings in detection of premalignant lesions of cervix in a tertiary care centre. Int J Sci Stud. 2015;3(8):55-60.
12. Chaudhary RD, Inamdar SA, Hari Haran C. Correlation of diagnostic efficacy of unhealthy cervix by cytology, colposcopy and histopathology in women of rural areas. Int J Reprod Contracept Obstet Gynaecol. 2014;3:2138.

13. IARC. World Cancer Report 2008; IARC: 2008.

14. Nayar R, Wilbul DC. The pap test and bethesda 2014. Acta Cytologica. 2015;59:121-32.

15. Gupta K, Malik NP. Prevalence of cervical dysplasia in western Uttar Pradesh, J Cytol. 2013;30(4):257-62.

16. Thulaseedharan JV, Malila N, Hakama M, Esmy PO Cheriyan M, Swaminathan R. Socio-demographic and reproductive risk factors for cervical cancer in rural India. Asian Pacific J Cancer Prev. 2012;13:2991-5.

17. Ashmita D, Shakuntala P.N, Rao SR. Comparison and correlation of Pap Smear, colposcopy and histopathology in symptomatic women and suspicious looking cervix in a tertiary hospital care centre. Int $\mathbf{J}$ Health Sci Res. 2013;3(5):50-9.

18. Sherwani RK, Khan T. Conventional Pap Smear and Liquid Based Cytology for Cervical Cancer Screeninga comparative study. J Cytol. 2007;24(4):167-72.

19. Barut MU. Analysis of sensitivity, specifity and positive and negative predictive value of smear and colposcopy in diagnosis of premalignant and malignant cervical lesions, Med Sci Monit. 2015;21:3860-7.

Cite this article as: Bhatnagar $\mathrm{K}$, Baghel $\mathrm{K}$. Epidemiology of patients with bad cervix attending gynaecology OPD of a tertiary care centre in Western Uttar Pradesh, India. Int J Reprod Contracept Obstet Gynecol 2017;6:791-6. 